\title{
Stable RK2-Derived Cloning Vectors for the Analysis of Gene Expression and Gene Function in Gram-Negative Bacteria
}

\author{
Bruno Dombrecht, Jos Vanderleyden, and Jan Michiels \\ F.A. Janssens Laboratory of Genetics, Katholieke Universiteit Leuven, B-3001 Heverlee, Belgium \\ Accepted 29 November 2000.
}

\begin{abstract}
The construction of several stable RK2-derived cloning vectors for the analysis of gene expression and function in gram-negative bacteria is reported. Plasmid stability is conferred by the RK2 par locus or by insertion of the sps $A B$ or spsCD symbiotic plasmid stability loci from pNGR234 $a$ of Rhizobium sp. NGR234. The vectors carry multiple cloning sites with protection against read-through transcriptional activity of vector sequences. Vector derivatives with the constitutive nptII promoter or a promoterless gusA gene are suitable for the study of gene function or regulation in bacteria.
\end{abstract}

Additional keywords: Azospirillum brasilense Sp245, postsegregational killing, pTR102, Rhizobium etli CNPAF512, y4dLM, y4mFE.

RK2-derivatives (IncP $\alpha$ ) such as pVK101, pLAFR3, and pRK415 are widely used as cloning vectors in the study of gram-negative, plant-associated bacteria (Keen et al. 1988; Knauf and Nester 1982; Staskawicz et al. 1987). These plasmids, however, are not always maintained stably in bacteria in the absence of antibiotic selection. This is illustrated by the plasmid loss in Rhizobium spp. bacteroids recovered from legume nodules, making the analysis of gene expression during symbiosis troublesome. Weinstein et al. (1992) countered this problem by cloning the RK2 broad-host-range plasmid stability locus (par) in a mini-RK2 plasmid. The resulting plasmid pTR102 was stably maintained in Sinorhizobium meliloti bacteroids. The same par locus also confers plasmid stabilization in Escherichia coli, Pseudomonas aeruginosa, Agrobacterium tumefaciens, Azotobacter vinelandii (Roberts and Helinski 1992), and Rhizobium etli CE3 (Taté et al. 1999). Plasmids use different mechanisms for their stable maintenance in bacteria such as active partitioning, multimer resolution, and postsegregational killing (Helinski et al. 1996). The RK2 par locus consists of two operons. The parCBA operon stabilizes plasmids in $E$. coli and several other gram-negative bacteria and encodes ParA, a resolvase; ParB, a nuclease; and ParC, a protein of unknown function (Easter et al. 1998; John-

Corresponding author: J. Michiels, Telephone: +32 16 329684; Fax: + 3216 321966; E-mail: jan.michiels@agr.kuleuven.ac.be son et al. 1999). The parDE operon encodes a postsegregational killing system, consisting of the ParD antitoxin and the ParE toxin (Johnson et al. 1996; Roberts et al. 1994). Many bacteria use postsegregational killing systems to retain their plasmids (Gerdes 2000; Rawlings 1999).

Major drawbacks of these RK2-derivatives are the relative absence of suitable cloning sites and the lack of protection against read-through transcriptional activity of vector sequences as experienced, for instance, in pLAFR3. In addition, pTR102 is not maintained stably in all species tested (see below). To overcome these problems, we modified pTR 102 (Weinstein et al. 1992) (Fig. 1). Before introducing a multiple cloning site (MCS), several restriction sites were removed from the vector. DNA preparation and recombinant DNA techniques were performed according to standard procedures (Sambrook et al. 1989). R. etli and S. meliloti were grown routinely at $30^{\circ} \mathrm{C}$ in TY supplemented with $7 \mathrm{mM} \mathrm{CaCl}_{2}$ and CM79 media (Michiels et al. 1998b), Azospirillum brasilense at $30^{\circ} \mathrm{C}$ in Luria-Bertani (LB) medium supplemented with 2.5 $\mathrm{mM} \mathrm{CaCl} 2$ and $2.5 \mathrm{mM} \mathrm{MgCl}_{2}$, and E. coli at $37^{\circ} \mathrm{C}$ in $\mathrm{LB}$ medium. First, the EcoRI site in pTR102 was removed by EcoRI digestion, blunting with Klenow DNA polymerase in the presence of the four deoxynucleoside triphosphates and subsequent ligation, yielding pTR102- $\Delta \mathrm{E}$. Next, the $0.2-\mathrm{kb}$ $K p n \mathrm{I}-P s t \mathrm{I}$ fragment was removed by KpnI-PstI digestion, blunting with T4 DNA polymerase and subsequent ligation, yielding pTR102- $\triangle$ EKSP (Fig. 1A). To introduce the MCS, primers Rhi-42 (5'-AGCTAGCCCGCCTAATGAGCGGGCT TTTTTTTGGCGCGAAGCTTTCTAGAGGATCCGGCGCG CCGCGGCCGCGTTAACGGCCGGCCGTTTAAACCTGC AGGAATTCGAGCTCGGTACCAACAAAAAAAAGCCCG CTCATTAGGCGGGCT-3') and Rhi-43 (5'-GATGAGCCCG CCTAATGAGCGGGCTTTTTTTTGTTGGTACCGAGCTC GAATTCCTGCAGGTTTAAACGGCCGGCCGTTAACGC GGCCGCGGCGCGCCGGATCCTCTAGAAAGCTTCGCG CCAAAAAAAAGCCCGCTCATTAGGCGGGCT-3') were annealed at room temperature, and the product was cloned in HindIII-BamHI digested pTR102- $\triangle \mathrm{EKSP}$, resulting in pFAJ1700 (Fig. 1B). The MCS of pFAJ1700 contains the following restriction sites: HindIII, XbaI, BamHI, AscI, NotI, HpaI, FseI, PmeI, PstI, EcoRI, SacI, and KpnI (Fig. 2A). The MCS is bordered by two $\operatorname{trp} A$ transcriptional terminators orientated on both sides toward the MCS. The use of these ter- 
minators in plasmids for gram-negative bacteria was reported previously by Wilson et al. (1995). pFAJ1700 was introduced in several bacterial species, as described by Michiels et al. (1998a), and the stability of the plasmid was assessed in the absence of antibiotic selection. Stability tests were carried out (Fig. 3). pFAJ1700 is retained $100 \%$ after 72 generations in $A$. brasilense Sp245, S. meliloti Rm1021, and R. etli CE3 (data not shown), but not in $R$. etli CNPAF512 (Fig. 3). These results confirm previous data obtained for $R$. etli CE3 (Taté et al. 1999) and $S$. meliloti (Weinstein et al. 1992) and adds $A$. brasilense $\mathrm{Sp} 245$ to the list of bacteria that stably maintain plasmids carrying the RK2 par locus. Strain variation in plasmid stability within the same species, as observed here for the $R$. etli strains CE3 and CNPAF512, was reported previously by Smith and Rawlings (1998) for the pas system of pTF-FC2 in different E. coli backgrounds. The reason for this variation is unknown, but it was noticed that in those strains where the pas system was most effective the PasB toxin was the most toxic. Furthermore, Roberts et al. (1994) observed that plasmids carrying the parDE operon lose their stability in the presence of the parD antitoxin gene in trans on a compatible plasmid. Thus, the presence of a parD like antitoxin gene on the chromosome of CNPAF512 or on a plasmid present in CNPAF512, but not in CE3 (Brom et al. 1992; F. A. Janssens Laboratory of Genetics, unpublished), could account for the instability of pFAJ1700 in R. etli CNPAF512.

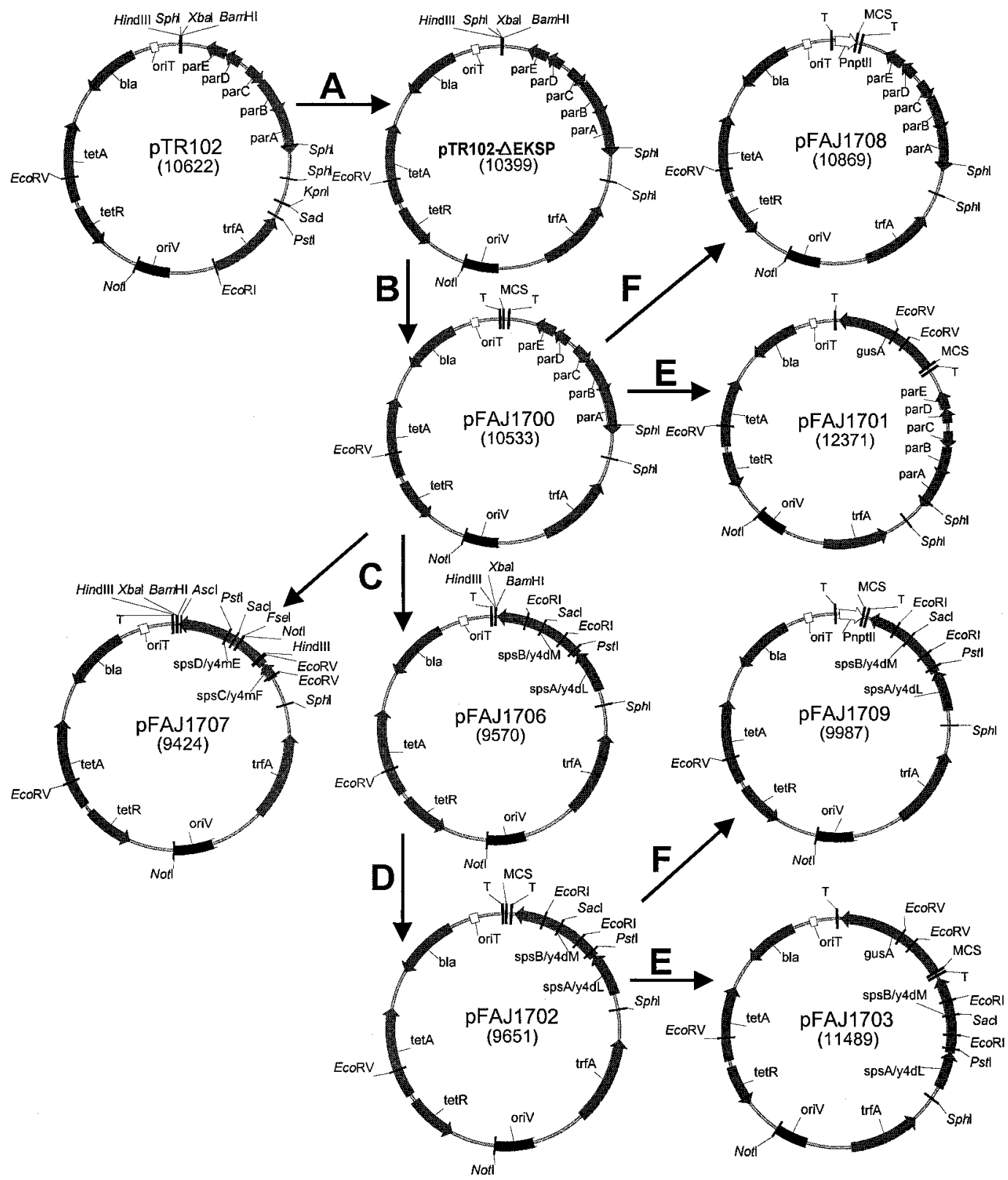

Fig. 1. Schematic representation of plasmid constructions, as described in text. Plasmid size (base pairs) is indicated between parentheses. Multiple cloning sites of plasmids are shown in detail in Figure 2. All plasmids shown encode resistance against tetracycline and ampicillin. bla encodes betalactamase (ampicillin resistance); tetA and tetR encode tetracycline resistance; trfA encodes replication initiation protein; and gusA encodes betaglucuronidase. oriV: origin of vegetative replication $(\mathrm{IncP} \alpha)$; oriT: origin of transfer; T: trpA: transcriptional terminator; PnptII: nptII promoter. 
In order to obtain plasmid stability in $R$. etli CNPAF512, two proposed postsegregational killing systems, y4dLM and y4mFE, from the symbiotic plasmid pNGR234a of Rhizobium sp. NGR234 (Falla and Chopra 1999; Freiberg et al. 1997) were envisaged. The loci were amplified by polymerase chain reaction (PCR) from total DNA of NGR234 with the Pwo polymerase, as described (Michiels et al. 1998b). The y4mFE genes were produced with primers BD-50 (5'-CTG AGGATCCGACGTGGAAGACAGCGGCTAAATCG-3'; the BamHI restriction site is underlined) and $\mathrm{BD}-51$ (5'TTCAGCATGCCCTCCCCGACGATC-3'; the SphI restriction site is underlined) and the y4dLM genes with primers BD-52 (5'-TTCAGCATGCGGTCTGCGCAGGTTGATCTG C-3'; the SphI restriction site is underlined) and BD-53 (5'CTGAGGATCCCGAGCCGCAAGGCACTACTTCG-3'; the BamHI restriction site is underlined). The PCR products obtained, $2.0 \mathrm{~kb}$ (y4dLM) and $1.9 \mathrm{~kb}$ (y4mFE), were adenylylated with Taq polymerase and dATP and subsequently cloned in pCRII-TOPO with the TOPO TA Cloning Kit (Invitrogen, Groningen, The Netherlands), resulting in pFAJ1704 and pFAJ1705, respectively. The correct DNA sequence of the PCR products was controlled by DNA sequencing on an ALFexpress sequencer (Pharmacia, Uppsala, Sweden) with fluorescein-labeled oligonucleotide primers. Finally, the $2.0-\mathrm{kb}$ $\mathrm{y} 4 \mathrm{dLM}$ and $1.9-\mathrm{kb}$ y $4 \mathrm{mFE}$ BamHI-SphI fragments from the respective pCRII-TOPO vectors were cloned into the corresponding sites of pFAJ1700, yielding pFAJ1706 and pFAJ1707, respectively (Fig. 1C). Stability tests were carried out in $R$. etli CNPAF512 (Fig. 3). y4dLM and y4mFE conferred $100 \%$ stability to the plasmids after 72 generations in free-living growth conditions and 3-week-old bacteroids, whereas pTR102 and pFAJ1700 (both containing the par locus from RK2) and pLAFR3 (lacking any stabilization locus) are not maintained stably. In view of these results and considering the homology of Y4dM and Y4mE to the HipA toxin (Falla and Chopra 1999), we propose the following acronym for these loci: sps (symbiotic plasmid stability locus), namely $\operatorname{sps} A B$ (y4dLM) and $\operatorname{sps} C D$ (y4mFE) (Fig. 1). So far there has been no clear evidence on how rhizobia retain their symbiotic plasmids without any obvious selection system in the absence of the plant. Rhizobium sp. NGR234 can be cured of pNGR234 $a$ yielding strain ANU256, which is viable, but not capable of symbiosis (Morrison et al. 1984). spsAB and spsCD are good candidates for postsegregational killer loci that ensure stable maintenance of pNGR234a. pFAJ1702 was derived from pFAJ1706 by cloning the annealing product of primers BD-59 (5'-AGCTTTCTAGAGGCGCGCCGTTAAC GGCCGGCCGTTTAAACGGATCCGGTACCAACAAAAA AAAGCCCGCTCATTAGGCGGGCT-3') and BD-60 (5'-GA TCAGCCCGCCTAATGAGCGGGCTTTTTTTTGTTGGTA CCGGATCCGTTTAAACGGCCGGCCGTTAACGGCGCG CCTCTAGAA-3') into HindIII-BamHI digested pFAJ1706 (Fig. 1D). The MCS of pFAJ1702 contains the following restrictions sites, HindIII, XbaI, AscI, HpaI, FseI, PmeI, BamHI, and $K p n \mathrm{I}$, and is bordered, as observed in pFAJ1700, by $\operatorname{trpA}$ transcriptional terminators (Fig. 2B).

gusA-fusion derivatives of pFAJ1700 and pFAJ1702 were constructed. A gusA gene preceded by a ribosome binding site was amplified by PCR from pRAJ260 (Metcalf and Wanner 1993) with the Pwo DNA polymerase and primers Rhi-44 (5'-ATGCAAGCTTGTTGATTCATTGTTTGCCTCC-3'; the HindIII restriction site is underlined) and Rhi-45 (5'-ATGC TCTAGATGACTAGCTAAGGAGGAGTCCCTTATGTTAC GTCCTG-3'; the $\mathrm{XbaI}$ restriction site is underlined, the ribosome binding site is in bold, and the start codon of gusA is italicized). The 1.8-kb PCR product was digested with HindIII and $X b a \mathrm{I}$, and the fragment was cloned into HindIII-XbaIdigested pFAJ1700 and pFAJ1702, yielding pFAJ1701 and pFAJ1703, respectively (Fig. 1E). To test the functionality of these vectors, the promoter of the $R$. etli CNPAF512 y4vC homolog was amplified by PCR with Pwo polymerase and primers Rhi-108 (5'-TCGAGGCGCGCCGGCGGCATTCTC TGTGAGC- $3^{\prime}$; the AscI restriction site is underlined) and Rhi-107 (5'-ATGAGGATCCCCTCGTCCACG-3'; the BamHI

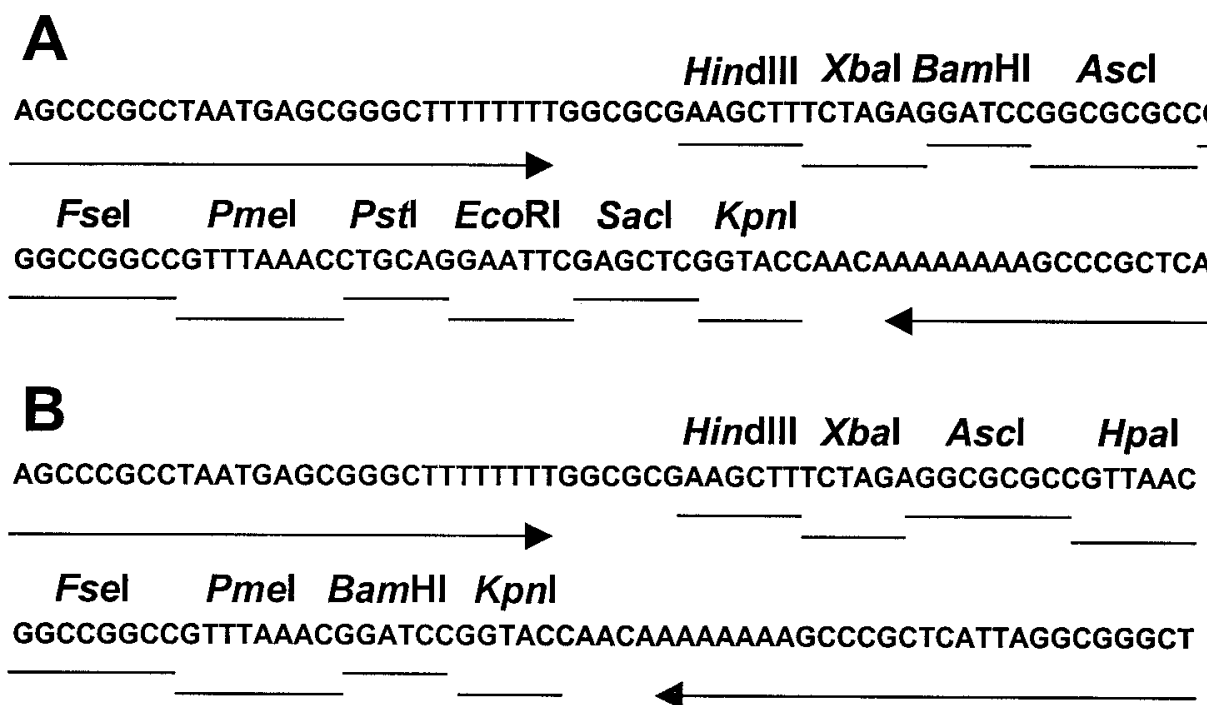

Fig. 2. Multiple cloning sites (MCS) of A, pFAJ1700, pFAJ1701, and pFAJ1708 and B, pFAJ1702, pFAJ1703, and pFAJ1709. Arrows indicate trpA transcriptional terminators. oriT borders the HindIII site, stabilization loci border the KpnI site in both MCS. gusA and PnptII are cloned as HindIII-XbaI fragments in the MCS. 
restriction site is underlined) and subsequently cloned AscIBamHI pFAJ1703. The resulting $\mathrm{y} 4 \mathrm{vC}-$ gus A fusion was conjugated to wild-type $R$. etli CNPAF512 and its nifA mutant background, Rp1000 (Michiels et al. 1994). Expression tests were carried out basically as described by Michiels et al. (1998a). The microaerobical expression of the R. etli $\mathrm{y} 4 \mathrm{vC}$ homolog in wild-type background amounted to approximately 1,200 Miller units, whereas the aerobical expression in CNPAF512 and Rp1000 as well as microaerobical expression in Rp1000 remained at a background level of approximately 20 Miller units.

pFAJ1700 and pFAJ1702 derivatives, allowing the overexpression of target genes, were constructed with the promoter of the nptII gene from Tn5. The suitability of the promoter of the neomycin phosphotransferase gene for overexpression in rhizobial background was described previously by Labes et al. (1990) and Xi et al. (1999). The nptII promoter was amplified by PCR from pUC18-2 (Michiels et al. 1991) with Pwo DNA polymerase and primers Rhi-94 (5'-ATGCAAGCTTCACGCT GCCGCAAGCACTCAGG-3'; the HindIII restriction site is underlined) and Rhi-95 (5'-CTGATCTAGAATCCTGTCTCT TGATCAGATCTTG-3' the $\mathrm{XbaI}$ restriction site is underlined). The $0.35-\mathrm{kb}$ PCR product was digested with HindIII and $X b a \mathrm{I}$ and cloned in HindIII-XbaI-digested pFAJ1700 and pFAJ1702, yielding pFAJ1708 and pFAJ1709, respectively (Fig. 1F). The functionality of these constructs was assessed by cloning of the gusA PCR product of Pwo polymerase and primers Rhi-61 (5'-ATGCGGATCCTGACTAGCTAAGGAG GAGTCCCTTATGTTACGTCCTG-3'; the BamHI restriction site is underlined, the ribosome binding site is in bold, and the start codon of gusA is italicized) and Rhi-47 (5'-ATGCGGTA CCGTTGATTCATTGTTTGCCTCC-3'; the KpnI restriction site is underlined) as a BamHI-KpnI fragment into pFAJ1708 and pFAJ1709. The resulting PnptII-gusA fusions showed an expression level of approximately 2,000 Miller units in an $E$. coli background.

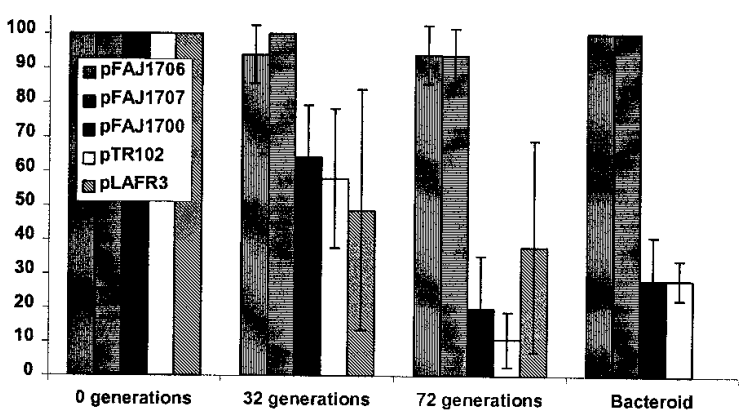

Fig. 3. Stability of different RK2-derived plasmids in Rhizobium etli CNPAF512. Strains were grown overnight in liquid TY with $1 \mu \mathrm{g}$ of tetracycline per $\mathrm{ml}$ at $30^{\circ} \mathrm{C}$. Subcultures were taken daily, diluted $1,000-$ fold, and grown in liquid TY for 10 days in the absence of tetracycline. After 0, 32, and 72 generations, samples were taken and dilutions were plated out on solid CM79 medium. After 2 days incubation at $30^{\circ} \mathrm{C}, 100$ colonies per strain were picked up and replicas were tested on solid CM79 medium, with or without tetracycline. Plasmid stability (percent of plasmid-containing cells) was determined as the fraction of tetracycline-resistant colonies. Bacteroids were isolated from Phaseolus vulgaris cv. Limburgse after 3 weeks, as described by Michiels et al. (1998b), and plated out on solid CM79. Replica plating and determination of plasmid stability were carried out as described above. Bacteroid stability of pLAFR3 was not determined. Values are the means of at least two independent experiments; error bars denote standard deviations.
In conclusion, we described the construction of several stable RK2-derived cloning vectors that can be used for the study of genes in a wide background of gram-negative bacteria. The plasmids carry the RK2 par stability locus or the $\operatorname{sps} A B$ or spsCD postsegregational killer loci from pNGR234a of Rhizobium sp. NGR234. The plasmids have MCS, which are protected against read-through transcriptional activity of vector sequences by the $\operatorname{trp} A$ transcriptional terminator. gusAfusion derivatives were constructed for the study of bacterial promoters. Also derivatives carrying the nptII promoter were made for the overexpression of genes.

\section{ACKNOWLEDGMENTS}

We thank A. Toukdarian and E. Luyten for their greatly appreciated help in reconstituting the nucleotide sequence of pTR102. B. Dombrecht is indebted to the Vlaams Instituut voor de Bevordering van het Wetenschappelijk-Technologisch Onderzoek in de Industrie for a predoctoral fellowship. J. Michiels is a postdoctoral fellow of the Fund for Scientific Research Flanders. The authors acknowledge financial support from the Flemish government (GOA98 to J. Vanderleyden).

\section{LITERATURE CITED}

Brom, S., Garcia-de-los-Santos, A., Stepkowsky, T., Flores, M., Davila, G., Romero, D., and Palacios, R. 1992. Different plasmids of Rhizobium leguminosarum bv. phaseoli are required for optimal symbiotic performance. J. Bacteriol. 174:5183-5189.

Easter, C. L., Schwab, H., and Helinski, D. R. 1998. Role of the parCBA operon of the broad-host-range plasmid RK2 in stable plasmid maintenance. J. Bacteriol. 180:6023-6030.

Falla, T. J., and Chopra, I. 1999. Stabilization of Rhizobium symbiosis plasmids. Microbiology 145:515-516.

Freiberg, C., Fellay, R., Bairoch, A., Broughton, W. J., Rosenthal, A., and Perret, X. 1997. Molecular basis of symbiosis between Rhizobium and legumes. Nature 387:394-401.

Gerdes, K. 2000. Toxin-antitoxin modules may regulate synthesis of macromolecules during nutritional stress. J. Bacteriol. 182:561-572.

Helinski, D. R., Toukdarian, A. E., and Novick, R. P. 1996. Replication Control and Other Stable Maintenance Mechanisms of Plasmids. Pages 2295-2324 in: Eschericha coli and Salmonella: Cellular and Molecular Biology. F. C. Neidhardt, R. Curtiss, J. L. Ingraham, E. C. C. Lin, K. B. Low, B. Maganasik, W. S. Reznikoff, M. Riley, M. Schaechter, and H. E. Umbarger, eds. ASM Press, Washington, DC.

Johnson, E. P., Strom, A. R., and Helinski, D. R. 1996. Plasmid RK2 toxin protein ParE: Purification and interaction with the ParD antitoxin protein. J. Bacteriol. 178:1420-1429.

Johnson, E. P., Mincer, T., Schwab, H., Burgin, A. B., and Helinski, D. R. 1999. Plasmid RK2 ParB protein: Purification and nuclease properties. J. Bacteriol. 181:6010-6018.

Keen, N. T., Tamaki, S., Kobayashi, D., and Trollinger, D. 1988. Improved broad-host-range plasmids for DNA cloning in gram-negative bacteria. Gene 70:191-197.

Knauf, V. C., and Nester, E. W. 1982. Wide host range cloning vectors: A cosmid clone bank of an Agrobacterium Ti plasmid. Plasmid 8:4554.

Labes, M., Puhler, A., and Simon, R. 1990. A new family of RSF1010derived expression and lac-fusion broad-host-range vectors for gramnegative bacteria. Gene 89:37-46.

Metcalf, W. W., and Wanner, B. L. 1993. Construction of new betaglucuronidase cassettes for making transcriptional fusions and their use with new methods for allele replacement. Gene 129:17-25.

Michiels, J., VandeBroek A., and Vanderleyden, J. 1991. Molecular cloning and nucleotide sequence of the Rhizobium phaseoli recA gene. Mol. Gen. Genet. 228:486-490.

Michiels, J., D'hooghe, I., Verreth, C., Pelemans, H., and Vanderleyden, J. 1994. Characterization of the Rhizobium leguminosarum biovar phaseoli nifA gene, a positive regulator of nif gene expression. Arch. Microbiol. 161:404-408.

Michiels, J., Van Soom, T., D’hooghe, I., Dombrecht, B., Benhassine, T., 
de Wilde, P., and Vanderleyden, J. 1998a. The Rhizobium etli rpoN locus: DNA sequence analysis and phenotypical characterization of rpoN, ptsN, and ptsA mutants. J. Bacteriol. 180:1729-1740.

Michiels, J., Moris, M., Dombrecht, B., Verreth, C., and Vanderleyden, J. 1998b. Differential regulation of Rhizobium etli rpoN2 gene expression during symbiosis and free-living growth. J. Bacteriol. 180:3620-3628.

Morrison, N. A., Cen, Y. H., Chen, H. C., Plazinski, J., Ridge, R., and Rolfe, B. G. 1984. Mobilization of a sym plasmid from a fast-growing cowpea Rhizobium strain. J. Bacteriol. 160:483-487.

Rawlings, D. E. 1999. Proteic toxin-antitoxin, bacterial plasmid addiction systems and their evolution with special reference to the pas system of pTF-FC2. FEMS Microbiol. Lett. 176:269-277.

Roberts, R. C., and Helinski, D. R. 1992. Definition of a minimal plasmid stabilization system from the broad-host-range plasmid RK2. J. Bacteriol. 174:8119-8132.

Roberts, R. C., Strom, A. R., and Helinski, D. R. 1994. The parDE operon of the broad-host-range plasmid RK2 specifies growth inhibition associated with plasmid loss. J. Mol. Biol. 237:35-51.

Sambrook, J., Fritsch, E. F., and Maniatis, T. 1989. Molecular Cloning: A Laboratory Manual. Cold Spring Harbor Laboratory, Cold Spring Harbor, NY, U.S.A.

Smith, A. S. G., and Rawlings, D. E. 1998. Efficiency of the pTF-FC2 pas poison-antidote stability system in Escherichia coli is affected by the host strain, and antidote degradation requires the lon protease. $\mathrm{J}$. Bacteriol. 180:5458-5462.

Staskawicz, B., Dahlbeck, D., Keen, N., and Napoli, C. 1987. Molecular characterization of cloned avirulence genes from race 0 and race 1 of Pseudomonas syringae pv. glycinea. J. Bacteriol. 169:5789-5794.

Taté, R., Riccio, A., Caputo, E., Cermola, M., Favre, R., and Patriarca, E. J. 1999. The Rhizobium etli trpB gene is essential for an effective symbiotic interaction with Phaseolus vulgaris. Mol. Plant-Microbe Interact. 12:926-933.

Weinstein, M., Roberts, R. C., and Helinski, D. R. 1992. A region of the broad-host-range plasmid RK2 causes stable in planta inheritance of plasmids in Rhizobium meliloti cells isolated from alfalfa root nodules. J. Bacteriol. 174:7486-7489.

Wilson, K. J., Sessitsch, A., Corbo, J. C., Giller, K. E., Akkermans, A. D., and Jefferson, R. A. 1995. Beta-glucuronidase (GUS) transposons for ecological and genetic studies of rhizobia and other gram-negative bacteria. Microbiology 141:1691-1705.

Xi, C., Lambrecht, M., Vanderleyden, J., and Michiels, J. 1999. Bifunctional $g f p$ - and $g u s A$-containing mini-Tn 5 transposon derivatives for combined gene expression and bacterial localization studies. J. Microbiol. Methods 35:85-92. 